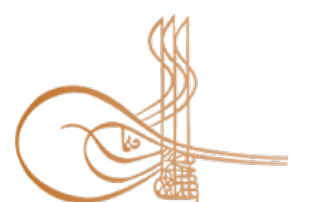

www.turkishstudies.net/social
Turkish Studies - Social Sciences

eISSN: 2667-5617

Research Article / Araștırma Makalesi

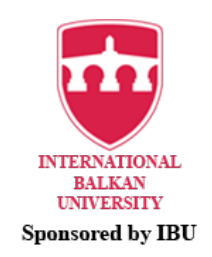

Sponsored by IBU

\title{
Siyasal İletişim ve Algı Yönetimi İlişkisi Bağlamında İran ve Amerika Krizi (amerikanınsesi.com ve sputniknews.com Haber Sitelerinin Kasım Süleymani’nin Öldürülmesi ile İlgili Haberin Verilişinin Eleştirel Söylem Analizi)
}

\author{
Iran and American Crisis in The Context of The Relationship of Political Communication and \\ Perception Managment \\ (A Critical Discourse Analysis of the Reporting of the News About the Killing of November \\ Süleymanman of the amerikaninsesi.com and sputniknews.com News Sites)
}

Emine Kılıçaslan*

\begin{abstract}
Rapid developments in media technology with the globalization process have opened the way for fast, easy and cheap transportation of information on the earth. The news, which has reached to the farthest places with radio technology, is being watched instantly with many tools such as television, internet and socal media as a result of the developments in mass communication technology. This rapid development in mass communication technology has provided important opportunities for those holding economic power to hold political power. In context, the sovereign states of the World send political messages and conduct perception management by using all kinds of media products to create public opinion through mass media. There is a purpose at the end of this process, which is sent through mass media and functions as a political communication process. This aim is to manage perception to create global public opinion. Today, this perception management can also be carried out by powerful states, political parties, NGO's governments, media bosses, arms and pharmaceutical companies. Various power focuses that hold the economic power and want to retain political power also apply to perception management over the media in power wars. In this context, in this study, critical discourse analysis method was applied and news related to Kasim Süleymani https://www.amerikanınsesi.com (VOA) and https://tr.sputniknews.com hnews sites were analyzed. Concepts related to perception management and political communication resulting from this analysis are shown in graphics.
\end{abstract}

Structured Abstract: Introduction: Perception management in the context of political communication is carried out especially through the media. Often in both news programs and other media products, political messages about perception management are perceived unknowingly by those watching the news.

In this context, in this study, the news "The murder of" Kasım Süleymani "between the USA and Iran was published on www.amerikaninsesi.com (VOA) and the Russian news website www.trsputniknews.com. The way this news is made is the subject of this study.

\footnotetext{
* Öğr. Gör. Dr. Aydın Adnan Menderes Üniversitesi, Aydın Meslek Yüksek Okulu, Basım Yayın Teknolojileri PhD, Aydın Adnan Menderes University, Aydın Vocational School, Publishing Technologies 
In this context, the aim of the study is to show the perception management in the context of political communication by showing how the news is done differently in both news sites by using discourse analysis technique. For this purpose, as a sample, the discourse analysis of how the news news of two different countries (USA and Russia), www.amerikaninsesi.com (VOA), and tr.sputniknews internet news channel "Killing the November Solomon", technique was analyzed. The importance of the study was investigated how the most objectively and objectively presented news carried perception management by carrying political messages.

As a result, when the way the news is given in the context of impartiality and objectivity, it is seen that the ideological tendency of the news channel in which the news takes place and the cultural structure in which it takes place plays a very important role in shaping that news.

In this context, in this study, the news of the murder of Kasım Süleymani was subjected to discourse analysis by taking into account the ideological perspectives of the United States and Russia in the internet news sites www.amerikaninsesi.com (VOA, www.sputniknews.com). In the research, meaning search was made in the words, concepts and sentences used while both news sites were giving news. In this search for meaning, the delivery of the news in both channels was examined from the ideology search framework in terms of perception management in the context of political communication. These were subjected to the same news comparative discourse analysis method on both different sites. Concepts related to perception management and political communication resulting from this analysis are shown in graphics.

The first graphic belongs to amerikaninsesi.com (VOA). The concepts that appear in this chart and are used the most are; "The elite troop of the Iranian Revolutionary Guards", "Commander of the Jerusalem Force", "The Game Has Changed", "The US can take action for preventive purposes", "A turning point in the Middle East", "Iran's harsh retaliation" shows that quite a lot of political message sentences have been established. Perception management was created by including emotional and thoughtful messages in these political messages.

Similarly, when looking at the second graphic of sputniknews in the context of political communication and perception management; Iran Crisis (Concept of Crisis), Hashdi Sabi, Hand Engineer, Commander of the Power of Jerusalem (the importance of Solomon), Ahl al-Hak leader Kays, Increase in Oil Prices (economic outcome of the crisis), al Hazali Badr Organization, Iraqis Freedoms, Iraqis Joy, It is noteworthy that the concepts of violence (emotional concepts), the Shiite Militia Group, Hadi al Amiri, Terror (increased confusion), the Middle East (emphasis on the region are used differently than the American website). Another point that draws attention is that by using a lot of news channels, In this context, sputnik news shows that it acts in the context of objectivity and impartiality by using both the data of the American AP news agency and the data of the Hashdi Sabi Spokesperson, Al Hadath channel, Al Mayadeen channel, US Department of Defense (Pentagon).

Chart 3 is important in terms of being a chart with the same concepts and sentences used in amerikaninsesi.com (VOA) and sputniknews news. The meaning we are looking for here shows how many times the same concepts are used in the news. This graphic is important to represent the focus of the news. The most used concept in the news is the reality that is emphasized the most. Accordingly, the most used in the concepts in the chart third, amerikaninsesi.com. (VOA) Repeating the name of November Solomon in the news 27 times sputniknews.com. He used it 34 times in the news.

In the graphic four, the different concepts used in giving the news of "Killing the November Solomon" are examined. In this chart, unlike amerikaninsesi.com (VOA) sputniknews; The concepts of Air Supported People's Streets, Mahdi, Distinguished Unity, Mark Esper, Game Changed, Turning Point, Hard Retaliation, Joy Shows, Active Plan, Attack Military Staff, Directed Attacks, were used differently. Sputniknews, on the other hand, in the news of "the killing of Kasım Süleyman"; Haşdi Şabi, (Haşdi Şabi, an organization that also fights in Syria, mostly composed of Shiite militia) Iraq, Ahl al-Hak leader Kays, (Iraq-based Shiite Militia Group: Asaib Ehl el Hak), Increase in Oil Prices (effects on the world economy), White House, Foreign Minister Mike Pompeo, Defense, Iranian, Israel, al-Khazali Badr Organization (Hadi Al-Amir-led Badr Organization), Iraqi Freedoms, Iraqis Joy, Violence (spread of violence in the region) USA 'Diplomats "differently.

Consequently, perception management in the context of political communication today is with global media institutions that are the result of the globalization process and contribute to globalization. These organizations deliver information to the world in the form of a network. The way to access information is with

Turkish Studies - Social, 15(4) 
just one button. Anyone who wants and provides certain sub-basic conditions can access these media tools especially by means of internet, cables and antennas. This situation especially boosts the appetite of global dominant political actors. Therefore, these global political actors conduct public diplomacy and political communication using the media through very naive and beautiful words, concepts and symbols. In this context, perceptions can be managed through political messages they send as they wish and global public opinion can be created.

Keywords: Political Communication, Perception Management, Political Actor, Internet Journalism.

Öz: Küreselleşme süreciyle birlikte medya teknolojisinde yaşanan hızlı gelişmeler bilginin yeryüzünde hızlı, kolay ve ucuz ulaşımının yolunu açmıştır. Sanayi Devrimi sonrası yaşanan hızlı teknolojik gelişim, kitle iletişim araçlarının gücünü artırmıştır. Önce radyo teknolojisi ile en ücra yerlere kadar ulaşan haber kitle iletişim teknolojisinde yaşanan gelişmeler sonucu bugün televizyon, internet, sosyal medya gibi pek çok araçla anında izlenmektedir. Kitle iletişim teknolojisinde yaşanan bu hızlı gelişme ekonomik gücü elinde bulunduranların siyasal gücü ellerinde tutmaları açısından oldukça önemli firsatlar sunmuştur. Bu bağlamda dünyaya egemen devletler kitle iletişim araçları aracılığıyla kamuoyu yaratmak için her tür medya ürününü kullanarak siyasal iletiler göndermektedir ve algı yönetimi yapmaktadır. Kitle iletişim araçları aracılığıyla gönderilen ve siyasal iletişim süreci olarak işleyen bu sürecin sonunda bir amaç bulunmaktadır. Bu amaç küresel kamuoyu yaratmak için algı yönetimi yapmaktır. Günümüzde bu algı yönetimini kullanan siyasal aktörler, güçlü devletler, siyasi partiler, Sivil Toplum Örgütleri, hükümetler, medya patronları, silah ve ilaç şirketleri olarak sıralanmaktadır. Ekonomik gücü elinde bulunduran ve siyasi gücüde elinde tutmak isteyen çeşitli güç odakları ve siyasal aktörler iktidar savaşlarında medya üzerinden algı yönetimine çok fazla başvurmaktadır. Bu bağlamda bu çalışmada söylem analizi yöntemi uygulanarak Kasım Süleymani ile ilgili haberler https://www.amerikaninsesi.com ve https://tr.sputniknews.com/ haber siteleri analiz edilmiștir. Bu analiz sonucu ortaya çıkan algı yönetimi ve siyasal iletişim ile ilgili kavramlar grafiklerle gösterilmiştir.

Anahtar Kelimeler: Siyasal İletişim, Alg1 Yönetimi, Siyasal Aktör, İnternet Haberciliği.

\section{Giriş}

Yüzyılın başından itibaren kitle iletişim teknolojisinde yaşanan gelişmeler çağımızın kaderini belirlemiş̧tir. Bu gelişmelere 1950’lerden sonra televizyonun katılmasıyla birlikte özellikle Hollywood filmleri dünya çapında yaygınlaşmaya başlamıştır. Yeni bir kitle iletişim aracı olan televizyonla tanışan gelişmekte ve geri kalmış ülke insanları büyülenerek medya kültürünün egemenliği altına girmiştir. Bu bağlamda medya sektörüne kim sahipse ideolojik anlamda onun istediği şekilde tüm medya ürünleri şekillenmektedir.

İşitsel ve görsel medya teknolojisinden önce belirli bir eğitim seviyesinde olan insanlar beyinlerini kitap ve gazete okuyarak doldururken ve algıları okuduklarına göre şekillenmektedir. Özellikle televizyonun insan hayatına girmesi ile birlikte hem görsel hem de işitsel olarak yaşanan bilgi bombardımanı insanların algılarına hükmetmeye başlamıştır. Ardından gelen bilgisayar teknolojisi, internet ve sosyal medya ile birlikte $\mathrm{X}, \mathrm{Y}$ ve $\mathrm{Z}$ kuşağı modern insanın bilgi bombardımanına tutulmuş hali olarak yaşamaktadır. Stupak ve Coren'e göre, dört bir yanı televizyon, telefon ve internet ile çevrelenmiş olan insanlar, kişisel anlamda, etkin ve anlık olarak elektronik ortamda da bilgi bombardımanına maruz kalmaktadırlar (Stupak, 2000: 254; Coren vd., 1993: 4). Çevremizde maruz kaldığımız bu bilgi bombardımanı duyu organlarımız aracılığıyla algılanmaktadır. Algıladığımız dış dünyaya ait verilerden bazıları beynimizde kültürel kodlar ve eski yaşam deneyimleri aracılığıyla işlenmektedir.

Medya kültürü olarak da tanımlayabileceğimiz bu iletişim sürecinin yoğun bilgi içermesi yeni insanın algılarına doğrudan etki yapmaktadır. Bilindiği gibi insan çevresindeki bilgiyi duyu organları aracılığıyla seçmektedir. Günümüz dünyasında milyonlarca enformasyona medya aracılığı ile maruz kalan insanlar bu enformasyon yağmuru karşısında savunmasız kalmaktadır. Bu bağlamda 
alg1 kavramına bakıldığında duyu organları aracılığıyla beyne giden komutların anlamlandırılma süreci olarak tanımlanmaktadır. Bu tanımdan yola çıkıldığında tanım aslında bir canlının biyolojik yapısı ile ilgilidir. Ayrıca insanların duyu organları ile çevreden gelen verilere göre algılanmasında kültür ve yaşam deneyimlerinin çok büyük önemi de bulunmaktadır.

Bireyin medya aracılığıyla maruz kaldığı çoğu enformasyon siyasal iletişim içermekte ve alg1 yönetimi yapmak için yapılmaktadır. Bu nedenle bu çalışmanın önemi 5N1K kuralına göre haberin tarafsızlığının siyasal iletişim bağlamında alg1 yönetimi nasıl yapıldığını göstermektir. $\mathrm{Bu}$ amaçla bu çalışmada söylem analizi yöntemi uygulanarak Kasım Süleymani ile ilgili haberler https://www.amerikaninsesi.com(VOA) ve https://tr.sputniknews.com/ haber siteleri karşılaştırılarak söylem analizine tabi tutulmuştur. Bu analiz sonucu ortaya çıkan algı yönetimi ve siyasal iletişim ile ilgili kavramlar aşağıda yer alan grafiklerle gösterilmiştir.

\section{Siyasal İletişim}

İletişimin siyasal kavramlar içeren ve iktidar olma amaciyla yapılan bir alanı olan siyasal iletişimin, en önemli özelliği belirli bir amacının olmasıdır. Hiç de masum olmayan bu amaç özellikle içinde egemenlik ve iktidar kavramlarını barındırmaktadır. Geçmişten bugüne insanların iktidar olma egemenlik kurma hırsı siyasal iletişim alanının ortaya çıkıp gelişmesinin önünü açmıştır. Örneğin, Coşkun'a göre, "siyasal aktörler sanat aracılığıyla bile egemenlik kurmuşlardır. Daha kolay iktidar olmuşlardır. İnsanların yöneten-yönetilen ilişkisi ile birlikte ortaya çıkan siyaset kavramı insanlık için daha eski bir yaratı olan sanatı da araç olarak her zaman kullanmıştır (Coşkun, 2019;170).

Buradan hareketle siyasal iletişime bakıldığında, Aziz'in tanımı bize yol göstermektedir. Ona göre, "belli ideolojik amaçlarını, belli gruplara, kitlelere, ülkelere ya da bloklara kabul ettirmek ve gerektiğinde eyleme dönüştürmek, uygulamaya koymak üzere siyasal aktörler tarafindan çeşitli iletişim tür ve tekniklerinin kullanılması ile yapılan iletişim"(Aziz, 2011;s.3) biçimine siyasal iletişim denilmektedir.

$\mathrm{Bu}$ tanım doğrultusunda bakıldığında "belirli ideolojik amaçlar belirli hedef kitlelere uygulanmaktadır" cümlesi siyasal iletişimin arkasındaki amacını anlatmaktadır. Burada amaç hedef kitlenin duyularını harekete geçirmek ve belirli bir düşünce sistemini canlı tutmaktır. Kısaca hedef kitlelere siyasal iletiler gönderilerek algı yönetimi yapılmaktadır. Bu algı yönetiminde hedef kitleye gönderilen kavramların hedef kitle tarafindan aşağıda yer alan süreçlerden geçerek düşünce sisteminde ideoloji olarak yer edebilmesi amaçlanmaktadır. Siyasal iletilerin gönderilerek alg1 yönetiminin harekete geçirilmesi sürecinde hedef kitlenin öncelikle siyasal iletiyi;

- Fark etmesi

- Dikkatle Dinlenmesi

- Etkilenmesi ve

- İkna Olmasi gerekmektedir.

Ancak o zaman amaca başarıyla ulaşıldığından bahsedilebilir. Fakat bu aşamalara geçilmeden önce yine hedef kitlenin gönderilen siyasal iletiye karşı duyarlı olması oldukça önem taşımaktadır. Örneğin milli duyguları ön planda olan bir kişinin algılamasında milliyetçilikle ilgili kavramlar ön plandadır. Bu kavramlardan herhangi birini duyan kişi algı yönelimi bu kavramlar doğrultusunda olduğu için herhangi bir siyasal iletide harekete geçebilmektedir.

Bir siyasal iletişim kampanyası yürütülürken her şeyden önce hedeflenen seçmen kitlesinin özelliklerinin bilinmesi gerekir. Hedeflenen seçmen kitlesinin sosyo-ekonomik ve sosyo-kültürel yapısı, eğitim durumu, gelir düzeyi, yerleşim yeri, yaş grupları, cinsiyetleri ve her şeyden önemlisi kullandıkları kitlesel iletişim araç ve teknikleri gibi hususların tespit edilmesi, siyasal iletişim kampanyalarının başarısını önemli ölçüde etkilemektedir. Kampanyanın ya da iletinin başarısı siyasal iletişim sürecinde, gönderilen iletinin içeriği ve yöntemi kadar ikna edicilik bağlamında zaman-mekân ilişkisi de önem taşımaktadır. 


\section{Algı Kavramı ve Algı Yönetimi}

Kavram olarak algı dışarıdan gelen bir uyarıcıyla ilgili farkındalıktır dışarıdan gelen uyarıcıların sinir akımları ile beyne ulaşması durumudur. Bu biyolojik çalışma sistemi felsefi anlamda "gerçek" kavramı ile kendisini bulmuştur. Gerçek nedir? Sorusu, felsefenin çokça üzerinde durduğu ve cevaplamaya çalıştığı kavramlardan bir olmuştur. Hançerlioğlu' na göre, "gerçek" bilinçten bağımsız, somut ve nesnel olarak var olandır. Somut ve nesnel olarak var bulunandır. Hakikat ise, gerçeğin bilinçteki yansısıdır (Hançerlioğlu,1997:214) Bir kişiye doğru gelen farklı durumlarda farklı kişilere doğru gelmeyebilir. Bu duruma şöyle bir açıklı getirilebilir. Kültür insanların gerçeklik algısında değișiklik yaratmaktadır. Kültürün içine doğan insan içinde bulunduğu kültürün kendi beyninde oluşturduğu ideolojik sistem ile düşündüğü için algısı da bu yönde şekillenmektedir. Bu bağlamda size doğru gelen bir şey bir başkasına doğru gelmeyebilir. Farklı kültürler ya da coğrafyalar kişilerin düşünce dünyasının şekillenmesinde rol oynamaktadır.

$\mathrm{Bu}$ tanım üzerinden hareketler çevreden gelen uyarıların zihinde yorumlanması ile oluşan alg1 gördüklerimizi, duyduklarımızı, tutum ve inançlarımızı belirlemektedir. Zihnimizde oluşan değer sistemleri doğduğumuz andan itibaren çevremizden gelen kültürel verilerle şekillenmektedir. Bu durum zihnimize gelen her verinin oluşmasında rol oynamaktadır. Bu bağlamda ayrıca kişinin beklentileri ve motivasyon uyarıları kişinin başlangıç bilgileri başka kişilerin davranış, tutum ve güdülerini sınıflandırarak anlamaya çalışması ve bilgilerini sürekli güncellemesi sosyal algılama faaliyeti sürecini işletmektedir. Leibniz'e göre de algı, bilinçdışı bir işlevdir. Gerçek anlamında, öznenin, kendisinin dışında olanı alması demektir. Bununla beraber ruhbilimciler ruhsal edimlerle ilgili olarak, dış algıya karşı bir de iç algıdan bahsetmektedirler (Felsefe Sözlüğü, 2005:1).

Bilindiği gibi algı yönetimi kavramı "ilk kez ABD Savunma Bakanlığı içindeki birimlerce kullanılmıştır. ABD siyasi kararlarının ülkede ve tüm dünya kamuoyunda benimsenmesi için kullanılan bir yöntem olarak ortaya atılmıştır (Özer, 2012;174). ABD’nde algı yönetimi kavramının ortaya atılmasında Amerikanın kendi hedefleri doğrultusunda dünyayı manipüle etmek ve egemenlik kurmak, yönetmek amaçları bulunmaktadır. Bu nedenle ABD özellikle kitle iletişim araçları üzerinden seçilen bilgilerin akışını kontrollü olarak yönetmektedir. Bu bağlamda algı yönetimi hedef kitlenin duygularını, düşünce biçimlerini ve nasıl güdüleneceklerini şekillendirme amacı gütmektedir. Özer'e göre "algılama yönetimi, çeşitli yolları kullanarak gerçekleri yansıtma, operasyon güvenliği sağlama, gerçeği izleme ve çarpıtma, psikolojik operasyonları yönetme gibi unsurların bileşkesinden oluşmaktadır (Özer, 2012; 176).

Yukarıda yer alan bilgilerin 1şığında bakıldığında ortaya çıkan durum kültürün içine doğan bireyin çevresi ile sürekli iletişim halinde olarak kültürden aldığ 1 verileri çevresi ile pekiştirmekte ve bu pekiştirme süreci bireyin algılamasında rol oynamaktadır. Bu durum göstermektedir ki bireyin, kültürün içinde çevresinden aldığı veriler ile düşünce sistemi yani ideolojik bakış açısı oluşmaktadır.

Alg1 yönetiminin işleyiş sürecine bakıldığında insanların mutlu oldukları zamanlarda yaşanmışlıklarını mutlu oldukları zaman hatırladıkları, acılı ve üzüntülü zamanlarda yaşanmışlıklarının acılı ve üzüntülü zamanlarda hatırladıkları görülmüştür. Bu bağlamda özellikle medya üzerinden yapılan siyasal iletiler duygusal veriler olarak gönderildiğinde algı yönetimi daha iyi işlemektedir. Bu bağlamda hedef kitleden istenilen destek sağlanabilmektedir. Tabi bu çalışma sisteminde doğru duygu verilerinin haberin içinde kullanılması oldukça önemlidir. Ayrıca gönderilen iletilerin hedef kitlenin içsel olarak kültür içinde geliştirdiği değerlerle verilerin uyuşması başarıyı sağlamaktadır.

Günümüzde bu şekillenmede en önemli rolü medya oynamaktadır. Özellikle medya aracılığıyla egemenlik kurma aslında egemen ideolojinin aktarımı sürecidir. Bu süreç var olan iktidarın devamı niteliğinde işlediği için sürekli medya kültürünün yaratılması gerekmektedir. Bir anlamda medya kültürü ile toplumun ve bireyin bilincinin biçimlendirilmesi (Kılıçaslan, 2019; 118) ve algının yönetimi olarak işlemektedir. 
Medya kültürü bağlamında bakıldığında medya ürettiği programlarla kültürel öğeler oluşturarak ideolojik veriler kullanmakta bu şekilde algı yönetimi yapmaktadır. Örneğin izlediğiniz herhangi bir Hollywood filmi "Özgürlük Heykeli” ile başlıyorsa aktörlerin konuşmalarında sıklıkla "burası özgür bir ülke" cümlesi geçiyorsa burada siyasal iletişim bağlamında alg1 yönetiminden söz edilebilmektedir.

Alg1 yönetimi süreci, herhangi bir medya aracı tarafından başlatılmışsa algılayan kişinin kişisel özellikleri ve geçmiş yaşam deneyimleri algılamayı etkileyecektir. Algılanan şeyin özellikleri, algılanma ortamı da bu etkiye destek verir.

Siyasal iletişim bağlamında bakıldığında örneğin bir siyasal aktörün nasıl tanındığ1 ve bu tanınmaya bağlı yorumlanması, anlaşılması alg1 yönetimini belirleyen faktörlerdendir. Bu nedenle bir siyasal aktör alg1 yönetimi yapmak istediğinde hedef kitlenin geçmiş yaşam deneyimleri ve gelecek beklentileri doğrultusunda siyasal iletiler gönderebildiği sürece başarılı olabilmektedir. Ayrıca algı yönetimi sürecinde hem geleneksel hem de medya kültürü harmanı yapılarak kültüre ait ideolojik iletiler gönderilerek öncelikle dikkat çekmek ardından manipülatif iletiler gönderilmektedir. Ayrıca algı yönetiminde soru sormak ve geri ileti almak önem taşırken sorunun cevabı genelde soruyu soran siyasal aktör tarafından verilmektedir. Russell, geri bildirim aynı zamanda alınan, verilen, yapılan değişiklikleri teşvik etmesi ve devam edilmesi için cesaretlendirmesi açısından algı yönetimine yardımcı olması bakımından önem taşır (Russell, 2001: 2) demektedir.

Siyasal iletişim açısından algı yönetimi bütün siyasal aktörler tarafından kamuoyu desteği almak açısından çok önemlidir. Bu süreç siyasal iletişimde iktidar olma egemenlik kurma sürecinin doğal sonucudur. İktidar olma sürecinde hedef kitle ile özdeşim kurmak bağlamında siyasal aktörün gönderdiği siyasal iletiler alg1 yönetiminin çerçevesini belirlemektedir. Siyasal aktörler hedef kitlelerini kültüre ait ideolojik iletilerle besleyerek aralarındaki bağı güçlü tutmak zorundadırlar. Örneğin bir siyasal aktör duygusal bağ kurmak için "şehit" "şehadet" "atalarımız" "bu topraklar" gibi kavramlarla hedef kitle üzerinde duygusal bağlamda siyasal iletişim kurabilmektedir. Hedef kitleden istenen geri bildirim alınmışsa algı yönetimi başarılı olmuş demektir. Kısaca siyasal iletişim bağlamında algı yönetimi hedef kitle, grup ya da toplumu istenilen düzeyde davranması için yapılmaktadır. Ayrıca gönderilen siyasal iletinin tutarlılı̆̆ 1 ve inandırıcılığ 1 da oldukça önemlidir. Sürekliliği olan, tutarlı ve inandırıcı mesajlar daha etkili olmaktadır. Bu mesajlar ile bireyin beyninde neyin doğru neyin yanlış olduğu değil neyin önemli neyin önemsiz olduğu bilgisi oluşturulmaktadır.

Özellikle devletlerarası ilişkilerde algı yönetimi egemen devletler tarafından yoğun bir şekilde kullanılmaktadır. Alg1 yönetimi konusunu; uluslar, ülkeler, hükümetler, askeri kurumlar ve işletmeler kullanabilmektedirler. Bu kapsamda böyle bir çalışma içinde olan kişi ya da kurumlar için alg1 yönetimini oluştururken ilk adım stratejik bir hedef belirlemektir (Callamari ve Reveron, 2003: 2).

Sonuç olarak küreselleşme süreci ile birlikte gelişen medya teknolojileri bireyi savunmasız hale getirmektedir. Günümüzde savunmasız hale gelen birey özellikle medya kültürünün etkisi ile siyasal iletişim bağlamında alg1 yönetimine karşı savunmasızıdır. Herhangi bir siyasal bilinci olmayan bireyler algı yönetimine yoğun maruz kalarak manipüle edilebilmektedir. Bu süreç küresel medya aracılığıyla bireylerin sürekli enformasyona tabi tutulması süreci ile işletilmektedir.

\section{Eleştirel Söylem Analizi}

Bilindiği gibi konuşma ve metin ile oluşturulan anlam ürünleri söylem analizi yöntemi ile analiz edilerek söylemin arkasındaki anlam araştırılmaktadır. Söylem analizi konuşma metinlerinin gizli ve yan anlamlarını çözümlemek için uygulanan bir analiz yöntemidir. Söylem analizi yönteminde metin ya da konuşma anlam, bağlam, yorum ve sonuç ilişkisi çerçevesinde analiz edilmektedir. Her söylemde ifade edilmek istenen temel bir düşünce, bir mesaj diğer bir ifadeyle 
ideoloji gizlidir Eagleton'un $(2011,257)$. Bilindiği gibi, söylem analizi konu odaklı bir yaklaşımdır. Özellikle sosyal alan araştırmalarında ve medya çalışmalarında kullanılmaktadır. Söylem analizi yönteminde, habere hangi kanaldan nasıl ulaştı̆̆ınız siyasal iletişim bağlamında önem taşımaktadır. Habere ulaşımda haberin veriliş tarzı direk algı yönetimi ile bağlantılıdır. Eleştirel söylem analizi ise yukarıda anlatılanlar bağlamında egemenlik, iktidar olma, güç kullanma, sınıf farkı, cinsiyet ayrımı gibi kavramların haberde nasıl kullanıldığını araştıran bir alt yöntemdir.

$\mathrm{Bu}$ çalışmada aşağıda yer alan grafiklerde www.amerikaninsesi.com.(VOA) sitesinden Amerika haberleri Amerika'da yaşanan gelişmeler, Türkiye-ABD ilişkileriyle ilgili haberler Türkçe olarak yer almaktadır. Bu nedenle Kasım Süleymani'nin öldürülmesi ile ilgili haberin veriliş tarzı ve haber verilirken seçilen sözcük, kavram ve cümlelerin kuruluşu siyasal iletişim bağlamında algı yönetimi çerçevesinde eleştirel söylem analizi çerçevesinde analiz edilmiştir. Aynı şekilde eleştirel söylem analizi bağlamında karşıt bir haber sitesi olarak sputniknews.com seçilmiştir. Bu nedenle Kasım Süleymani'nin öldürülmesi ile ilgili haberin sputniknews' de veriliş tarzı ve haber verilirken seçilen sözcük, kavram ve cümlelerin kuruluşu siyasal iletişim bağlamında alg1 yönetimi çerçevesinde eleştirel söylem analizine tabi tutulmuştur. Çalışmanın devamında her iki haber sitesinin haberi veriş tarzındaki aynılıklar ve farklılıklar siyasal iletişim bağlamında algı yönetimi açısından tekrar eleştirel söylem analizi çerçevesinde karşılaştırılmıştır.

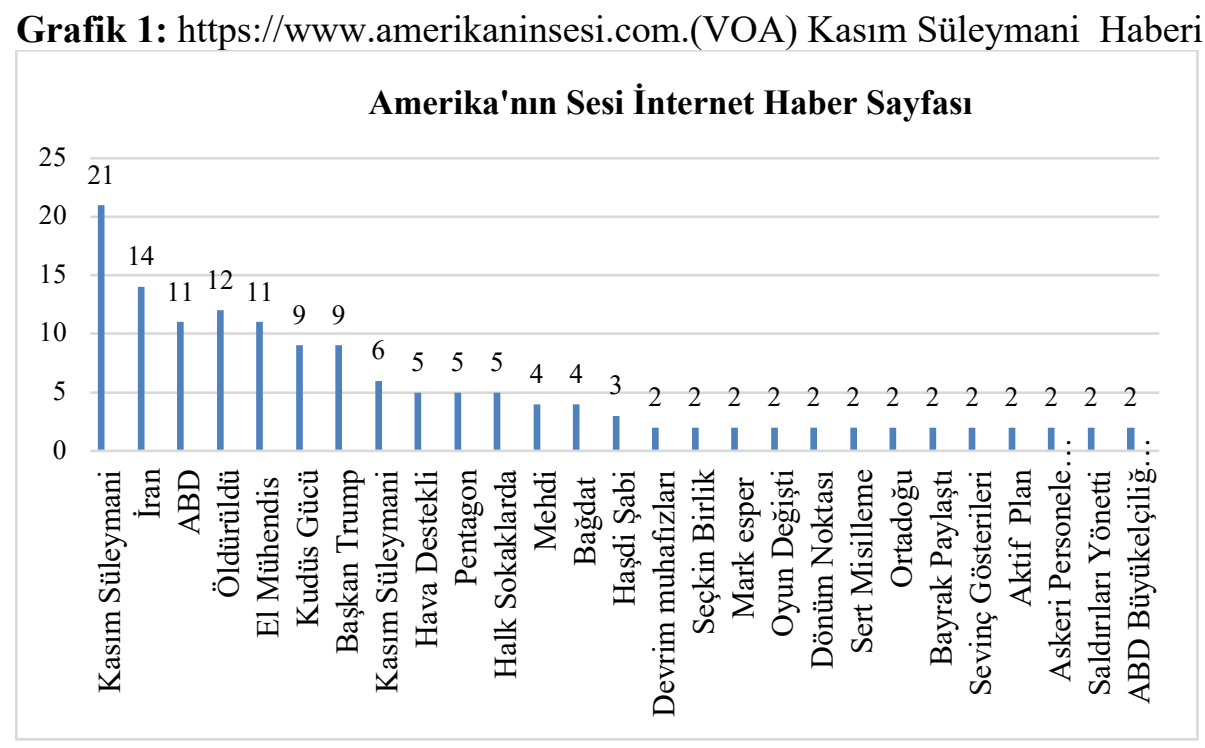

Amerikanınsesi haber sitesinin Kasım Süleymani haberine bakıldığında haberin içinde en fazla kullanılan kavramdan en az kullanılana göre sıralama; Kasım Süleymani, İran, ABD, öldürüldü, El Mühendis, Başkan Trump, Hava Destekli, Pentagon, Halk Sokaklarda (Iraklıların sevinç gösterileri kast edilmektedir) Mehdi, Bağdat, Haşdi Şabi, Devrim Muhafızları, Seçkin Birlik, Mark Esper, Sert Misilleme, Ortadoğu, Bayrak Paylaştı (Turmp'ın Twitter'dan paylaştığı Amerikan Bayrağ1 (zafer), Sevinç Gösterileri (rraklılar), Aktif Plan (Amerikan'ın stratejisi), Askeri Personele Saldırı, ABD Büyükelçiliği Onayladı, olarak devam etmiştir.

\section{- Haberin başlığı "Kudüs Gücü Komutanı Süleymani ABD Operasyonunda} Öldürüldü”

“İran Devrim Muhafizları'nın seçkin birliği olarak bilinen Kudüs Gücü Komutanı Kasım Süleymani ve İran destekli Halk Seferberlik Güçleri komutan yardımcısı Mehdi El Mühendis Irak'ın başkenti Bağdat'ta ABD'nin düzenlediği hava saldırısında öldürüldü. ABD Savunma Bakanlığı 
(Pentagon) Süleymani'nin Başkan Trump'ın talimatı doğrultusunda düzenlenen hava saldırısında öldürüldüğünü açıkladı. ABD Savunma Bakanı Mark Esper İran'la yaşanan gerilimle ilgili dün yaptığı açıklamada "Oyun değişti” diyerek ABD'nin önleyici amaçlı harekete geçebileceğinin mesajını vermişti. Süleymani ve El Mühendis' in ölümünün Ortadoğu'da bir dönüm noktası olacağı ve İran'ın sert bir misilleme ile karşılık vermesinin bekleneceği yorumları yapılıyor." https://www.amerikaninsesi.com/, E.T. 04.03.2020.

Oldukça tarafsız kavramlar kullanılarak yazılan bu habere eleştirel söylem analizi bağlamında bakıldığında, "İran Devrim Muhafızları'nın seçkin birliği”, "Kudüs Güicü Komutanı", "Oyun Değiş̧ti”, "ABD'nin önleyici amaçlı harekete geçebileceği”, "Ortadoğu'da bir dönüm noktası" , "İran'ın sert bir misilleme" aslında oldukça fazla siyasal ileti cümlesi kurulduğunu göstermektedir. Bu siyasal iletiler içinde duygusal ve kişisel düşünceye ait mesajlar barındırarak alg1 yönetimi oluşturulduğu görülmektedir.

Grafik 2: https://tr.sputniknews.com/, Kasım Süleymani Haberi

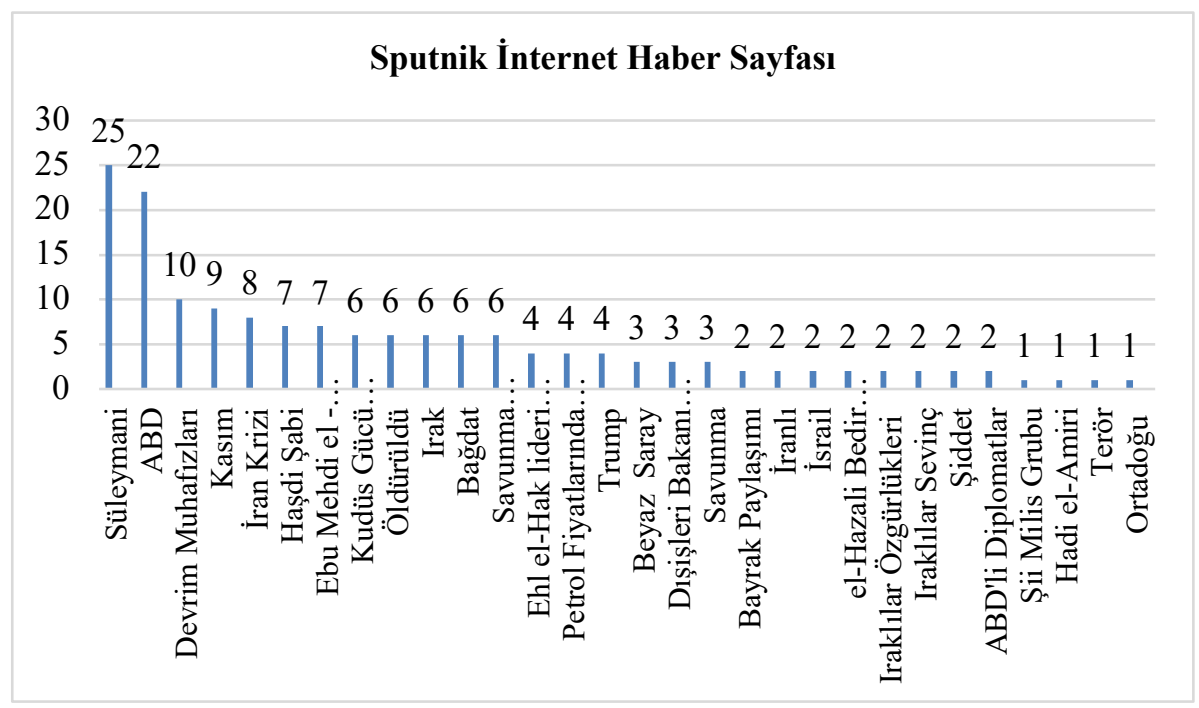

Sputniknews haber sitesinin Kasım Süleymani haberine bakıldığında haberin içinde en fazla kullanılan kavramdan en az kullanılana göre sıralama; Süleymani, ABD, Devrim Muhafızları, İran Krizi, Haşdi Şabi, El Mühendis, Kudüs Gücü Komutanı, Öldürüldü, Irak, Bağdat, Savunma Bakanlığı (Pentagon), Ehl el-Hak lideri Kays, Petrol Fiyatlarında Artış, Trump, Beyaz Saray, Dışişleri Bakanı Mike Pompeo, Savunma, Bayrak Paylaşımı, İranlı, İsrail, el Hazali Bedir Örgütü, Iraklılar Özgürlükleri, Iraklılar Sevinç, Şiddet, ABD'li Diplomatlar, Şii Milis Grubu, Hadi el Amiri, Terör, Ortadoğu, olarak sonlanmıştır. Haberin veriliş tarzına bakıldığında ise amerikanınsesi internet haber sayfası ile oldukça ortak noktalar taşıdığı görülmektedir.

\section{Süleymani Öldürüldü: ABD üstlendi” \\ Haberin Başlığı "İran Devrim Muhafızları Kudüs Gücü Komutanı Kasım}

Akşam saatlerinde Bağdat Uluslararası Havaalanı'na düzenlenen füze saldırısı sonrasında İran Devrim Muhafızları'na bağlı Kudüs Gücü Komutanı Kasım Süleymani ve Haşdi Şabi Genel Komutan Yardımcısı Ebu Mehdi el-Mühendis'in öldürüldüğü bildirildi.

Irak devlet televizyonundan yapılan açıklamada, "Kasım Süleymani ile Haşd Şabi Heyeti Başkanı Ebu Mehdi el-Mühendis, Bă̆gat Uluslararası Havaalanı yolunda araçlarını hedef alan bir füze saldırısı sonucu öldü". 
Amerikan AP haber ajansına konuşan Iraklı üst düzey yetkililer ise saldırıda Süleymani'nin yanı sıra Irak'taki Şii milis grubu Haşdi Şabi'nin Komutan Yardımcısı Mehdi el-Mühendis ve örgütün havalimanı protokol görevlisi Muhammed Rıza dahil 7 kişinin hayatını kaybettiğini bildirdi. Iraklı yetkililer, el-Mühendis'in Bağdat Havaalanına Süleymani'yi karşılamak için bir konvoyla geldiğini ve saldırının ise havaalanının kargo kısmına İranlı komutanın karşılandığ yerde yapıldığını kaydetti.

Haşdi Şabi Sözcüsü Ahmed el-Esadi, yaptı̆̆ı açıklamada "Kasım Süleymani ve elMühendis'in öldürülmesinden düşman ABD ve İsrail sorumlu" ifadelerini kullandı.

Öte yandan Al Hadath kanalı, Haşdi Şabi'ye bağlı Asaib Ehl el-Hak lideri Kays elHazali ve Bedir Örgütü lideri Hadi el-Amiri'nin Bağdat'ın Cediriye semtinde ABD deniz piyadeleri tarafından tutuklandığı bilgisini verdi. Bilgi, Al Mayadeen kanalınca yalanlandı.

ABD Savunma Bakanlığı (Pentagon) yetkilileri ise Kasım Süleymani'nin öldürüldüğü yönündeki haberleri doğruladı.

Pentagon'dan yapılan yazılı açıklamada, "ABD ordusu, Başkan'ın talimatı ile ABD tarafından yabancı terör örgütü olarak tanınan İran Devrim Muhafızları Ordusu Kudüs Gücü'nün Komutanı Kasım Süleymani'yi öldürerek (bölgedeki) ABD personelini korumak için kararlı ve savunma amaçlı bir adım atmıştır" ifadeleri kullanıldı. https://tr.sputniknews.com/, E.T.04.03.2020).

İkinci grafiğe siyasal iletişim ve algı yönetimi bağlamında bakıldığında; İran Krizi (Kriz kavramı), Haşdi Şabi, EI Mühendis, Kudüs Gücü Komutanı(Süleymani'nin önemi), Ehl elHak lideri Kays, Petrol Fiyatlarında Artış (krizin ekonomik sonucu), el Hazali Bedir Örgütü, Irakl1lar Özgürlükleri, Iraklılar Sevinç, Şiddet (duygusal kavramlar), Şii Milis Grubu, Hadi el Amiri, Terör( karışıklığın artması), Ortadoğu (bölgeye vurgu). Bu siyasal iletiler içinde duygusal ve düşünceye ait mesajlar barındırarak algı yönetimi oluşturulduğu görülmektedir.

Grafik 3: amerikaninsesi.com(VOA) ve sputniknews haberlerinde kullanılan (aynı kavramlar ve cümleler)

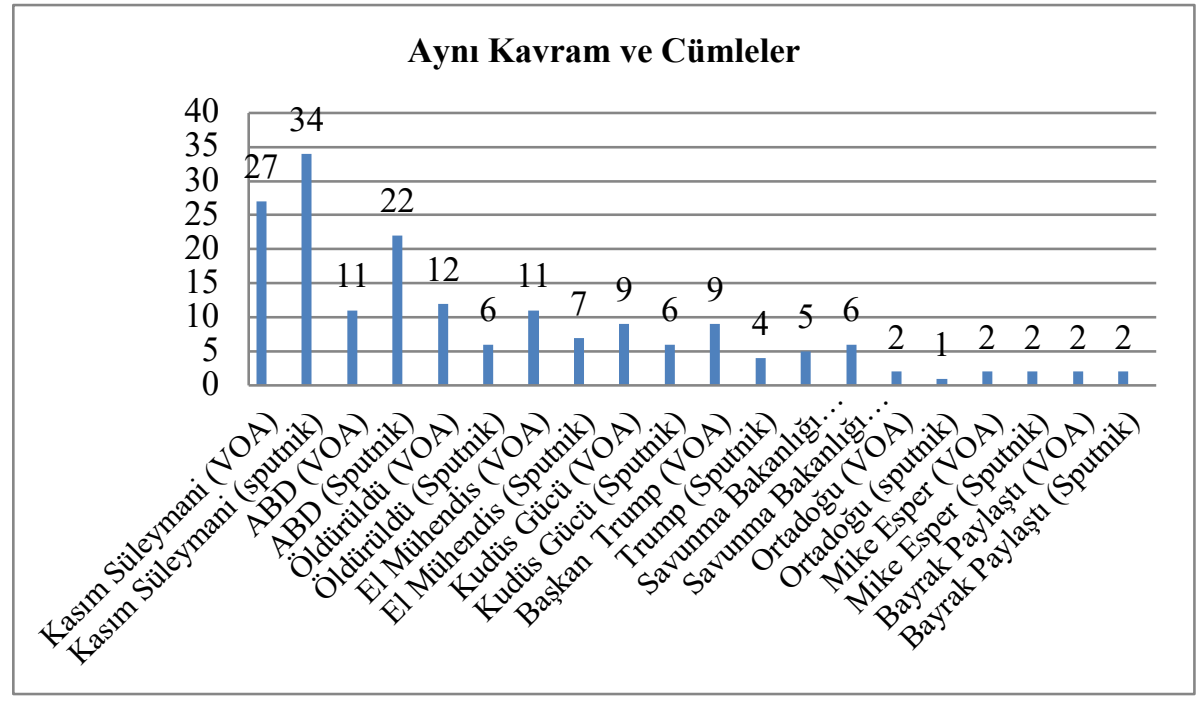

Grafik 3, amerikaninsesi.com(VOA) ve sputniknews haberlerinde kullanılan aynı kavram ve cümlelerin yer aldığ 1 grafiktir. Grafik üçte yer alan kavramlarda en fazla kullanılanlar değil aynı kullanılan kavramlar yan yana gösterilmiştir. Buna göre, amerikaninsesi.com. (VOA) Kasım Süleymani sözcüğünü 27 defa haber içinde tekrar ederken sputniknews.com. 34 defa haber içinde 
kullanmıştır. Zaten sputnik news'in haberi veriş tarzına bakıldığında hem Amerikan AP haber ajansının verilerini hem de Haşdi Şabi Sözcüsü, Al Hadath kanalı, Al Mayadeen kanalı, ABD Savunma Bakanlığı (Pentagon) verilerini kullanarak objektiflik ve tarafsızlık bağlamında hareket ettiğini göstermiştir.

Yukarıda yer alan grafik üçte her iki haber sitesinde yer alan Kasım Süleymani haberinde aynı olarak kullanılan kavramların kullanım frekansları gösterilmiştir. Bu bağlamda bakıldığında her iki internet haber sitesinde haberin hazırlanışında yukarıda yer alan 21 kavram aynı kullanılmıştır.

Bilindiği gibi hem siyasal iletişim hem de algı yönetimi ile ilgili medya ürünlerinde verilmek istenen mesaj alt iletilerde gizlidir. Burada bakılması gereken nokta aynılıklar değil farklılıklardır. Haberin yazılışında kullanılan aynı kavram ve sözcükler haber temel iskelet yapısına aittir. Haberin iskelet yapısının üstüne iliştirilen farklı sözcük ve kavramlar ise o haberin ideolojik anlamını yansıtmaktadır. Aşağıda yer alan grafik dörtte aynı amerikaninsesi ve sputniknews'te farklı kavramlarla nasıl verildiği görülmektedir.

Grafik 4: amerikaninsesi.com ve sputniknews haberlerinde kullanılan farklı kavram ve cümleler.

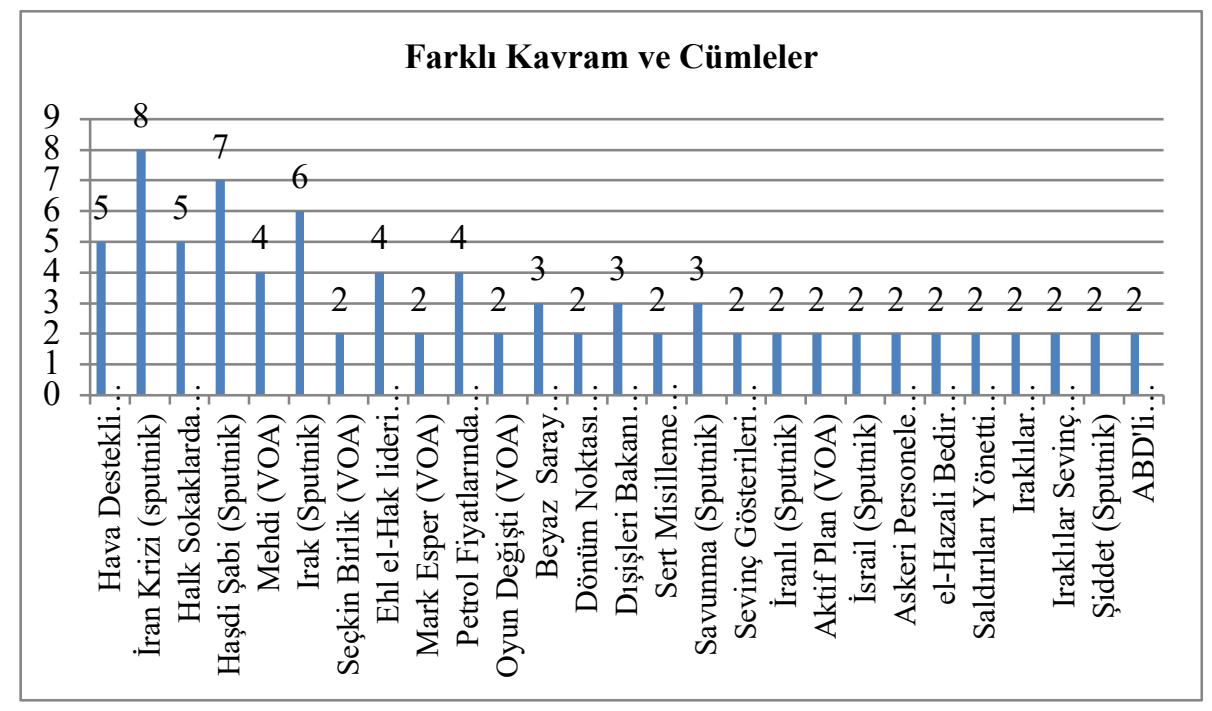

Grafik dört bize amerikanınsesi kanalının Kası Süleymani’nin nasıl öldürüldüğünü haberde (hava destekli, Iraklılar sokakta, sevinç gösterileri, seçkin birlik, oyun değişti, dönüm noktası, sert misilleme) gibi kavramları kullanarak gücünü göstermeye çalışmaktadır. Sputniknews'e bakıldığında (İran krizi, Haşdi Şabi, Ehl el-Hak lideri Kays, petrol fiyatlarında artış, savunma, elHazali Bedir Örgütü, Şiddet) gibi kavramları kullanarak olayı daha farklı boyutlara taşımıştır. Bu boyutlardan birincisi, İran krizi söylemidir. İkincisi bölgedeki farklı anti Amerikan'c1 islami örgütlerden bahsetmiştir. Üçüncü boyut ise ekonomik krizi tırmandırma üzerinedir.

\section{Sonuç}

Sonuç olarak bir haberin veriliş biçimine tarafsızlık ve objektiflik bağlamında bakıldığında haberin yer aldığı haber kanalının ideolojik eğiliminin ve içinde bulunduğu kültürel yapının o haberin şekillenmesinde oldukça önemli rol oynadığı görülmektedir.

$\mathrm{Bu}$ bağlamda bu çalışmada Kasım Süleymani'nin öldürülme haberi www.amerikaninsesi.com(VOA, www.sputniknews.com) internet haber sitelerinde sinde Amerika Birleşik Devletleri'nin ve Rusya'nın ideolojik bakış açıları göz önünde bulundurularak eleştirel 
söylem analizine tabi tutulmuştur. Araştırmada eleştirel söylem analizi çerçevesinde her iki haber sitesinin haberi verir iken kullandığı sözcük, kavram ve cümlelerde güç, iktidar, ayrımcılık gibi anlam aramaları yapılmıştır. Bu anlam aramalarında her iki kanalda haberin verilişine siyasal iletişim bağlamında algı yönetimi açısından ideoloji arama çerçevesinden bakılmıştır. Bu her iki farklı sitede yer alan aynı haber karşılaştırmalı eleştirel söylem analizi yöntemine tabi utulmuştur. $\mathrm{Bu}$ analiz sonucu ortaya çıkan alg1 yönetimi ve siyasal iletişim ile ilgili kavramlar grafiklerle gösterilmiştir.

Birinci grafik amerikaninsesi.com (VOA) ya aittir. Bu grafikte ortaya çıan ve en fazla kullanılan kavramlar; "İran Devrim Muhafızları'nın seçkin birliği”, "Kudüs Gücü Komutanı", "Oyun Değiş̧t”", "ABD'nin önleyici amaçlı harekete geçebileceği”, "Ortadoğu'da bir dönüm noktası" "İran'ın sert bir misilleme" bizlere aslında oldukça fazla siyasal ileti cümlesi kurulduğunu göstermektedir. Bu siyasal iletiler içinde duygusal ve düşünceye ait mesajlar barındırarak algı yönetimi oluşturulmuştur.

Aynı şekilde sputniknews'e ait ikinci grafiğe siyasal iletişim ve algı yönetimi bağlamında bakıldığında; İran Krizi (Kriz kavramı), Haşdi Şabi , El Mühendis, Kudüs Gücü Komutanı(Süleymani'nin önemi), Ehl el-Hak lideri Kays, Petrol Fiyatlarında Artış (krizin ekonomik sonucu), el Hazali Bedir Örgütü, Iraklılar Özgürlükleri, Iraklılar Sevinç, Şiddet (duygusal kavramlar), Şii Milis Grubu, Hadi el Amiri, Terör( karışıklığın artması), Ortadoğu (bölgeye vurgu kavramlarının amerikaninsesi internet haber sitesinden daha farklı olarak kullanıldığ dikkat çekmektedir. Ayrıca bir dikkat çeken diğer nokta ise habere ulaşımda çok fazla haber kanalından yararlanarak haberi vermeleri olmuştur. Bu bağlamda sputnik news' in haberi veriş tarzına bakıldığında hem Amerikan AP haber ajansının verilerini hem de Haşdi Şabi Sözcüsü, Al Hadath kanalı, Al Mayadeen kanalı, ABD Savunma Bakanlığı (Pentagon) verilerini kullanarak objektiflik ve tarafsızlık bağlamında hareket ettiğini göstermiştir.

Grafik 3, amerikaninsesi.com(VOA) ve sputniknews haberlerinde kullanılan aynı kavram ve cümlelerin yer aldığı grafik olması açısından önemlidir. Burada aradığımız anlam aynı kavramların haber içinde kaç defa kullanıldığını göstermektedir. Haberin odak noktasını temsil etmesi açısından bu grafik önemlidir. Haberde en fazla kullanılan kavram en fazla öne çıkarılan gerçeklik olarak karşımıza çıkmaktadır. Grafik üçte yer alan kavramlarda en fazla kullanılanlar. Buna göre, amerikaninsesi.com. (VOA) Kasım Süleymani'nin ismini 27 defa haber içinde tekrar ederken sputniknews.com. 34 defa haber içinde kullanmıştır.

Grafik dörtte ise "Kasım Süleymani'nin öldürülmesi” haberin verilişinde kullanılan farklı kavramlara bakılmıştır. Bu grafikte, amerikaninsesi.com (VOA)sputniknews' den farklı olarak; Hava Destekli, Halk Sokaklarda, Mehdi, Seçkin Birlik, Mark Esper, Oyun Değişti, Dönüm Noktası, Sert Misilleme, Sevinç Gösterileri, Aktif Plan, Askeri Personele Saldırı, Saldırıları Yönetti, kavramlarını farklı olarak kullanılmıştır. Sputniknews' ise, "Kasım Süleymani'nin öldürülmesi" haberinde; Haşdi Şabi, (Haşdi Şabi, büyük bölümü şii milislerden oluşan Suriye'de de savaşan bir örgüt) Irak, Ehl el-Hak lideri Kays, (Suriye'de Savaşan Irak Kökenli Şii Milis Grup: Asaib Ehl el Hak), Petrol Fiyatlarında Artıș (Dünya ekonomisine etkileri), Beyaz Saray, Dışişleri Bakanı Mike Pompeo, Savunma, İranlı, İsrail, el Hazali Bedir Örgüttï (Hadi el-Amiri liderliğindeki Bedir Örgütii), Iraklılar Özgürlükleri, Iraklılar Sevinç, Şiddet (bölgede şiddetin yaygınlaşması) ABD'li Diplomatlar" kavramlarını farklı olarak kullanmıştır.

Sonuç olarak bakıldığında günümüzde siyasal iletişim bağlamında algı yönetimi küreselleşme sürecinin sonucunda ortaya çıkan ve küreselleşmeye de katkıda bulunan küresel medya kuruluşları ile olmaktadır. Bu kuruluşlar bir ağ şeklinde tüm dünyaya bilgi ulaştırmaktadır. Bilgiye ulaşmanın yolu sadece bir tuş ile olmaktadır. İsteyen ve belirli alt temel koşulları sağlayan herkes özellikle internet, kablolar, antenler gibi araçlar aracılığıyla bu medya araçlarına ulaşabilmektedirler. Bu durum özellikle küresel egemen siyasal aktörlerin iştahını kabartmaktadır. Bu nedenle bu küresel siyasal aktörler çok naif ve güzel sözcükler, kavramlar ve semboller aracıllğıyla medyayı kullanarak 
kamu diplomasisi ve siyasal iletişim yapmaktadırlar. Bu bağlamda istedikleri şekilde gönderdikleri siyasal iletilerle alg1 yönetimi yapabilmekte ve küresel kamuoyu yaratılabilmektedir.

\section{Kaynakça}

Aziz Aysel, (2011), Siyasal İletişim, Nobel Yayıncılık.

Callamari, P., Reveron, D., (2003). China's Use of Perception Management, International Journal of Intelligence and CounterIntelligence, 16, ss.1-15. DOI :10.18535/ijsrm

Coren, S., Ward, L.M., Enns, J.T., (1993). Sensation and Perception, Harcourt Brace College Publishers.

Coşkun, S., K1lıçaslan, E., (2019), Siyasal İletişimde Güncel Yaklaşımlar, Kit. Böl. Gösterge Bilim Yaklaşımı Bağlamında Sanat ve Siyasal İletişim İlişkisi, Paradigma Akademi.

Eagleton, T. (2011). İdeoloji. Özcan, M. (Çev.), Ayrıntı Yayınları.

Felsefe Sözlüğü (2005). Algl ve Diğer Kavramlar, www.felsefe.gen.tr (20.02.2020).

Hançerlioğlu Orhan, (2000), Felsefe Sözlüğ̈̈, Remzi Kitapevi.

Kılıçaslan Emine, (2008), Siyasal İletişim ideoloji ve Medya İlişkisi, Paradigma Kitapevi.

Özer, M. A., (2012), Bir Modern Yönetim Tekniği Olarak Algılama Yönetimi ve İç Güvenlik Hizmetleri, Karadeniz Araştırmaları • Bahar 2012 • Say1 33 • 147-180, DOI: 10.12787/ KARAM1467..

Stupak, R.J., (2000). Perception Management: An Active Strategy for Marketing and Delivering Academic Excellence, Business Sophistication, and Communication Successes, Public Administration \& Management, 5 (4), ss.250-260.https://doi.org/10.1111/j.14678500.1992.tb02614 .x.

Russell, J.S., (2001). Are You Managing Perception? Leadership and Management in Engineering, April 2001. 33,45. DOI:10.5430/jms.v2n3p21

https://www.amerikaninsesi.com(VOA), E.T. 04.03.2020.

https://tr.sputniknews.com/, E.T. 04.03.2020. 